\title{
Foreword
}

\section{Anesthesia at the Edge of Life}

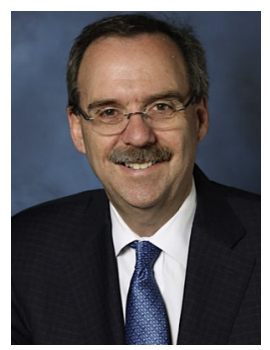

Lee A. Fleisher, MD, FACC

Consulting Editor

Anesthesiology has been lauded for being a leader in patient safety with an amazing record of markedly reducing deaths directly attributable to the delivery of surgical anesthesia. These advancements have led surgeons and other proceduralists to perform procedures on increasingly ill individuals. Many of these individuals would have died without a procedure several decades ago, but increasingly, the skill of anesthesiologists in the operating room and intensive care units has led to surviving these physiologic insults. In this issue of the Anesthesiology Clinics, innovations in perioperative management of extreme conditions and the ethical issues, including resourcelimited areas, are discussed.

In order to assemble a series of articles for Anesthesia at the Edge of Life, I enlisted an editor with much experience in the area and an editor of several previous issues of the Clinics, Stanley H. Rosenbaum, MA, MD. Dr Rosenbaum is Professor of Anesthesiology, Internal Medicine, and Surgery. He is Vice-Chair for Academic Affairs and Section Chief of Perioperative and Adult Anesthesia. In addition, he taught me how to provide anesthesia care for patients at the edge of life. He is joined by his colleague, Ranjit Deshpande, MBBS. Dr Deshpande is Assistant Professor of Anesthesiology and Director of Transplant Anesthesiology at Yale School of Medicine. Together, they have assembled an all-star group of authors to educate in this area.

Lee A. Fleisher, MD, FACC Perelman School of Medicine

University of Pennsylvania 3400 Spruce Street, Dulles 680

Philadelphia, PA 19104, USA

E-mail address:

lee.fleisher@uphs.upenn.edu 